\title{
Post-operative fever in children undergoing mastoidectomy due to complicated acute mastoiditis
}

\author{
Oren Ziv ${ }^{1}$, Aviad Sapir ${ }^{1}$, Eugene Leibowitz ${ }^{1}$, Sofia Kordeluk ${ }^{1}$, Daniel KAPLAN ${ }^{2}$, and Sabri \\ El-Saied ${ }^{3}$ \\ ${ }^{1}$ Soroka Medical Center \\ ${ }^{2}$ Soroka University Medical center \\ ${ }^{3}$ SoSoroka University Medical Center
}

March 1, 2021

\begin{abstract}
Abstract Objectives: To determine the immediate post-operative course and outcome of pediatric patients with complicated acute mastoiditis (CAM) following surgical treatment. Study Design: A retrospective chart review of children diagnosed with CAM who underwent mastoid surgery during 2012-2019. Setting: Tertiary care university hospital. Participants: the study includes 33 patients, divided into two groups: 17 patients with subperiosteal abscess (SPA) alone - single complication group (SCG) and 16 patients with SPA and additional intracranial or intratemporal complications -multiple complications group (MCG). Main Outcome Measures: post-operative fever course and pattern (POF). Results :33 patients belong to the SCG $17(51 \%)$ and $16(49 \%)$ belonged to the MCG, respectively. 6/17(35.3\%) SCG patients experienced POF vs. $12 / 16(75 \%)$ in the MCG $(\mathrm{P}=0.012)$. At post-operative day 2 (POD2), 10/13(77\%) febrile patients belonged to MCG and 3/13(23\%) to SCG $(\mathrm{P}=0.013)$. POF was recorded until POD6 in both groups. Seven patients, all from MCG with POF, underwent second imaging with no new findings. Conclusion: Following a cortical mastoidectomy for CAM, POF is not unusual in the first 6 days and seem to be benign condition. POF is more common, higher, and persistent for a longer duration in MCG compared with SCG. At POD 6, fever is expected to normalize in both groups, so if fever persists further evaluation should be considered.
\end{abstract}

\section{Key points:}

1. Thirty-three patients with complicated acute mastoiditis from a tertiary medical center were included in this retrospective cohort study.

2. Patients were divided into two study groups: Patients with sub-periosteal abscess alone- single compilation group, and patients with additional complications- multiple complication group.

3. Post-operative fever after cortical mastoidectomy due to complicated acute mastoiditis seems to be a benign condition in the 5-6 days postoperative period

4. The multiple complication group exhibited higher and prolonged post-operative fever compared to single complication cases.

\section{Introduction}

The most Common complications seen in children with acute mastoiditis include sub-periosteal abscess (SPA), sigmoid sinus thrombosis (SST), peri-sinus fluid/abscess, epidural, subdural abscess, and acute meningitis ${ }^{(1-2)}$. These complications are diagnosed both, clinically and radiologically ${ }^{(3)}$. Cortical mastoidectomy with ventilation tube insertion has a vital role in treating complicated mastoiditis (CAM), along with antibiotics ${ }^{(4)}$, antipyretics, and anticoagulation, in cases of SST ${ }^{(5)}$. 
The management of a febrile child with CAM regardless of clinical improvement becomes challenging. In such cases, repeated imaging and revision surgery should be considered. However, imaging in such circumstances possesses several limitations; Post-contrast head CT in children usually requires general anesthesia and is associated with substantial ionizing radiation. Head MRI is superior over CT for evaluating soft tissue details such as of peri-sinus abscess and presence of SST but is less available, costly, and requires an extended general anesthesia period.

The main aim of the present study was to characterize the incidence and course of post-operative fever (POF) in children with CAM following surgery

\section{Materials and methods}

The STROBE methodology Guidelines were applied in this cohort retrospective study.

\subsection{Ethical considerations:}

The study was approved by [Blinded for review] Medical Center's Ethics committee.

\subsection{Participants}

patients that underwent cortical mastoidectomy due to complicated mastoiditis at [Blinded for review] between 2012- 2019 were reviewed. Data collected included demographics, laboratory parameters at admission and at surgery day.

\subsection{Fever}

Post-operative body temperature was assessed every eight hours via rectal or axillary route and fever was defined as any body temperature of $[?] 38.0^{\circ} \mathrm{C}$.

\subsection{Treatment and complication grouping}

Single complication group (SCG) included all children diagnosed with acute mastoiditis and isolated SPA. Multi complications group (MCG) included patients with additional intratemporal or intracranial complication (peri-sinus fluid/abscess, epidural abscess, SST, acute meningitis).

\subsection{Statistical analysis}

Patient characteristics are presented as mean SD for continuous variables with normal distribution and categorical variables presented as a percentage. Continuous variables were examined using the student's ttest. Categorical variables were compared using the chi-square test. Data were analyzed using the Statistical Package for Social Sciences (IBM SPSS Chicago, USA, version 22). In all analyses, alpha level was set to 0.05 .

\section{Results}

\subsection{Demographics and inflammatory parameters at presentation}

Thirty-three patients with CAM who underwent a cortical mastoidectomy and ipsilateral ventilation tube insertion were identified. Demographics and clinical data are shown in Table 1 . Hospitalization length was significantly higher in MCG, $(12.4 \pm 6.6$ vs $.7 .5 \pm 2.5$ days in the SCG P $=0.008)$. WBC counts and CRP values at admission were 19,782 cells $/ \mathrm{mm}^{3}$ and $124.25 \mathrm{mg} / \mathrm{dl}$ in the SCG compared with $16,524 \mathrm{cells} / \mathrm{mm}^{3}$ and $129.19 \mathrm{mg} / \mathrm{dl}$ in the $\mathrm{MCG}$, respectively $(\mathrm{P}=0.229$ and $\mathrm{P}=0.89$, respectively). No significant differences were found between study groups regarding mean body temperature measurements, CRP levels, and WBC counts recorded on the day of surgery.

\subsection{Timing of surgery and laboratory findings}

Surgery was performed on days 1-5 of hospitalization (three patients on day 1, eighteen on day 2, eight on day 3 , three on day 4 , and one on day 5 ), with no difference between the groups in respect to mean timing for surgery ( $2.47 \pm 0.8$ days after admission in the $\mathrm{SCG}$ vs . $2.37 \pm 0.9$ days in the MCG, $\mathrm{P}=0.766)$. 


\subsection{Imaging}

All patients underwent post-contrast head CT and temporal bone high resolution CT (TBHRCT) prior to surgery. Imaging demonstrated 17 (51\%) children with isolated SPA alone, six (18\%) SPA with SST, four (12\%) SPA with peri-sinus collection, four (12\%) SPA, SST and peri-sinus collection. One (3\%) child had SST with epidural abscess and one (3\%) child had SPA with epidural abscess.

\subsection{Post-operative fever}

Both SCG and MCG exhibited POF, yet magnitude and duration significantly differed between the two groups as shown in (Figure 1),6/17(35.3\%) SCG patients experienced fever at some point post-operatively vs . $12 / 16(75 \%)$ in the MCG $(\mathrm{P}=0.012)$.

POF was higher and of longer duration in the MCG. At post-operative day (POD 1) mean temperature was $37.8 \pm 0.9$ in the $\mathrm{SCG}$ and $37.7 \pm 1$ in the MCG $(\mathrm{P}=0.71)$. On POD2, the mean temperature was lower in the SCG vs . the MCG (37.29 vs . 38.17, $\mathrm{P}=0.035)$. On POD6, the mean temperature was lower in the SCGvs . the MCG (37.44 vs . 37.58, respectively, $\mathrm{P}=0.32$ ).

Febrile children $\left([?] 38^{0} \mathrm{C}\right)$ in both groups are depicted in Figure 2. At POD2, 10/13 (77\%) febrile patients belonged to MCG and 3/13 (23\%) belonged to SCG $(\mathrm{P}=0.013)$. On POD6, only one child from the SCG had fever. This child had undergone another CT scan, and no new complications were found.

\subsection{Repeated imaging and surgery}

Seven of the 33 patients required a second imaging study performed on average on POD5, and all belonged to MCG. The indication for performing second imaging was continuous fever. No new complications were found on any of the repeated imaging. Five patients (15\%) underwent second surgical procedure, performed after an average time of 4 days following the first surgery. Four of them were from MCG and an additional single patient was from SCG. One patient had an examination under anaesthesia, and two additional patients had reinsertion of a VT. Two (6\%) patients underwent a second surgical procedure due to prolonged POF.

\section{Discussion}

The present study addresses the detailed post-operative course of fever in pediatric patients presented with CAM and underwent surgical treatment.

Most AM cases are managed conservatively, with myringotomy, intravenous antibiotics, and a careful followup, until resolution of the disease. In cases of complications, either extra or intra-cranial, surgery is generally indicated, while continuing systemic antibiotic treatment. The surgical management may differ between various medical centers and includes myringotomy, placement of VT, and incision plus drainage of SPA, with or without cortical mastoidectomy ${ }^{(6)}$. In a series of 570 children published recently from Israel, reported a significant increase in AM cases that had an indication for surgical intervention during the years 2008-2017 (11\% vs. $19 \%$ between the first and the last five years of the study respectively, $\mathrm{P}=0.008$ ) and described higher fever, leukocytes counts and CRP values in CAM compared to simple AM ${ }^{(7)}$. A study from the $\mathrm{UK}^{(8)}$, described 30 patients (aged 2 months to 15 years) with intracranial complications of AM. The most frequent complication was SST (73\%), followed by a cerebral abscess (40\%) and SPA (33\%). Three (10\%) patients had long-term sequelae (one developed secondary intracranial hypertension, the second a CSF leak that required placement of a ventriculo-peritoneal shunt, and the third with diplopia and residual mild visual obscuration); only one (3\%) patient required additional surgical treatment. In a recent study from the United States, addressing the safety and post-operative adverse events encountered during the management of $\mathrm{AM}{ }^{(9)}, 113$ patients with AM requiring surgical treatment were analyzed. Four (3.1\%) patients required readmission and $9(6.9 \%)$ required unplanned subsequent operative procedures.

\section{POF and infection}

POF is a known entity in surgery in general and in ear surgery in particular. El-Saied et al . (10) reported an overall POF incidence of $19.2 \%$ after cochlear implant surgery and showed that POF was unrelated 
to infectious or local complications and did not seem to have any long-term significance. Nevertheless, in contrast to the AM cochlear implants is an elective and "clean" procedure. In the setting of CAM; an acute infectious disease requiring surgery for purulent drainage and reduction of bacterial load, POF may be a sign of complications, requiring further investigation and treatment. To the best our knowledge our present study is the first to characterize the POF course of CAM. We found that POF is different in magnitude and duration in SCG and in MCG. We found that in any given POD in the MCG, the fever tended to be more common and higher. Nevertheless, around POD6, no differences were recorded in the values of fever measured between the two study groups, and the fever normalized in most of the patients. This is an important finding, suggesting that in a patient with CAM, POF should be expected and does not necessarily mean lack of control of the infection that would require repeated imaging and possibly revision surgery.

\section{Repeated-imaging and revision-surgery}

Twenty-one percent (7/33) of the study patients underwent post-surgery imaging; of them, only two patients required a second surgical procedure. All patients underwent post-surgical imaging belonged to the MCG. The most common findings in the repeated imaging showed only the previously known complications and post-surgical changes. Therefore, our study confirmed that a low percentage of patients with CAM might require repeated imaging and revision surgery. However, since fever usually continues in the first few PODs, waiting and close clinical follow-up for at least 5to 6 days after surgery seems to be sufficient in most cases before considering additional diagnostic and therapeutic steps.

\section{Conclusions}

Following a cortical mastoidectomy for CAM, POF is not unusual in the first 6 days and seem to be benign condition. However, POF is more common, higher, and persistent for a longer duration in MCG compared with SCG. At POD 6, fever is expected to normalize in both groups, so if fever persists further evaluation should be considered.

\section{Data Availability Statement}

The data that support the findings of this study are available from the corresponding author upon reasonable request.

\section{References}

1. Loh R, Phua M, Shaw CL. Management of paediatric acute mastoiditis: systematic review. J Laryngol Otol . 2018; 132:96-104. doi:10.1017/S0022215117001840

2. Ren Y, Sethi RKV, Stankovic KM. Acute Otitis Media and Associated Complications in United States Emergency Departments. Otol Neurotol . 2018; 39:1005-1011. doi:10.1097/MAO.0000000000001929

3. Mather MW, Yates PD, Powell J, Zammit-Maempel I. Radiology of acute mastoiditis and its complications: a pictorial review and interpretation. J Laryngol Otol . 2019; 1-6. doi:10.1017/S0022215119001609

4. Mierzwiński J, Tyra J, Haber K, et al. Therapeutic approach to pediatric acute mastoiditis - an update. Braz J Otorhinolaryngol . 2019; 85:724-732. doi:10.1016/j.bjorl.2018.06.002

5. Mather M, Musgrave K, Dawe N. Is anticoagulation beneficial in acute mastoiditis complicated by sigmoid sinus thrombosis? Laryngoscope . 2018; 128:2435-2436. doi:10.1002/lary.27151

6. Ghadersohi S, Young NM, Smith-Bronstein V, Hoff S, Billings KR. Management of acute complicated mastoiditis at an urban, tertiary care pediatric hospital. Laryngoscope. 2017; 127:2321-2327. doi: 10.1002/lary.26365.

7. Stern Shavit S, Raveh E, Levi L, Sokolov M, Ulanovski D. Surgical intervention for acute mastoiditis: 10 years experience in a tertiary children hospital. Eur Arch Otorhinolaryngol. 2019; 276:3051-3056. doi:10.1007/s00405-019-05606-2 
8. Krishnan M, Walijee H, Jeurasa A, et al. Clinical outcomes of intracranial complications secondary to acute mastoiditis: The Alder Hey experience. Int J Pediatr Otorhinolaryngol. 2020; 128: 109- 115. doi:10.1016/j.ijporl.2019.109675.

9. Crowson MG, Cheng J. Safety and post-operative adverse events in management of acute mastoiditis in children - 30 Day NSQIP outcomes. Int J Pediatr Otorhinolaryngol. 2018; 108:132-136. doi:10.1016/j.ijporl.2018.02.043

10. El-Saied S, Joshua BZ, Abu Tailakh M, et al. Early post-operative fever in paediatric patients undergoing cochlear implant surgery. Clin Otolaryngol . 2018; 43:385-388. doi:10.1111/coa.13009

Figure/Table list:

Figure 1.

Fever patterns in CAM; comparison between SCG and MCG

Figure 2.

Post-operative fever [?]38 ${ }^{\circ}$; SCG and MCG patients

Table 1. 33 children with complicated acute mastoiditis; demographic, clinical, laboratory and management parameters

\begin{tabular}{|c|c|c|c|c|}
\hline & Total $n=33$ & SCG $n=17$ & MCG $n=16$ & P-Value \\
\hline $\begin{array}{l}\text { Sex: Male n }(\%) \\
\text { Female } \mathrm{n}(\%)\end{array}$ & $\begin{array}{l}15(45.45) 18 \\
(54.54)\end{array}$ & $9(53) 8(47)$ & $6(37.5) 10(62.5)$ & 0.373 \\
\hline $\begin{array}{l}\text { Ethnicity: Jewish n } \\
\text { (\%) Bedouin } \mathrm{n}(\%)\end{array}$ & $23(69.7) 10(30.3)$ & $\begin{array}{l}11(64.7 \%) 6 \\
(35.3 \%)\end{array}$ & $12(75) 4(25)$ & 0.52 \\
\hline $\begin{array}{l}\text { Age at } \\
\text { hospitalization } \\
(\text { mean } \pm \mathrm{SD})\end{array}$ & $2.63( \pm 3.05)$ & $2.25( \pm 2.83)$ & $3.04( \pm 3.31)$ & 0.469 \\
\hline $\begin{array}{l}\text { Hospitalization } \\
\text { length (days, mean } \\
\pm \mathrm{SD})\end{array}$ & $9.9( \pm 5.46)$ & $7.52( \pm 2.57)$ & $12.43( \pm 6.6)$ & 0.008 \\
\hline $\begin{array}{l}\text { Fever at } \\
\text { admission }\left(\mathrm{C}^{\circ}\right. \\
\text { mean } \pm \mathrm{SD})\end{array}$ & $38.30( \pm 1.22)$ & $38.12( \pm 1.1)$ & $38.5( \pm 1.35)$ & 0.386 \\
\hline $\begin{array}{l}\text { WBC at } \\
\text { admission } \\
(\text { cells } / \text { mm } 3 \text {, mean } \\
\pm \text { SD) }\end{array}$ & $18,203( \pm 7,677)$ & $19,782( \pm 7,101)$ & $16,524( \pm 8,130)$ & 0.229 \\
\hline $\begin{array}{l}\text { CRP at admission } \\
(\mathrm{mg} / \mathrm{dl}, \text { mean } \pm \\
\mathrm{SD})\end{array}$ & $126.72( \pm 95.15)$ & $124.25( \pm 102.9)$ & $129.19( \pm 93.17)$ & 0.891 \\
\hline $\begin{array}{l}\text { Fever at day of } \\
\text { surgery }\left(\mathrm{C}^{\circ}, \text { mean }\right. \\
\pm \mathrm{SD})\end{array}$ & $37.96( \pm 1.15)$ & $37.93( \pm 1.05)$ & $37.98( \pm 1.27)$ & 0.899 \\
\hline $\begin{array}{l}\text { WBC at day of } \\
\text { surgery } \\
\left(\text { cells } / \mathrm{mm}^{3}, \text { mean }\right. \\
\pm \mathrm{SD})\end{array}$ & $16,583( \pm 6,807)$ & $14,562( \pm 6,613)$ & $18,154( \pm 6,908)$ & 0.311 \\
\hline $\begin{array}{l}\mathrm{CRP} \text { at day of } \\
\text { surgery }(\mathrm{mg} / \mathrm{dl} \text {, } \\
\text { mean } \pm \mathrm{SD})\end{array}$ & $104.0( \pm 93.2)$ & $95.15( \pm 35.9)$ & $114.12( \pm 96.2)$ & 0.639 \\
\hline
\end{tabular}


CRP - C-reactive protein, WBC- white blood count, SCG - single complication group, MCG - multiple complications group

Figure 1. Fever patterns in CAM; comparison between SCG and MCG

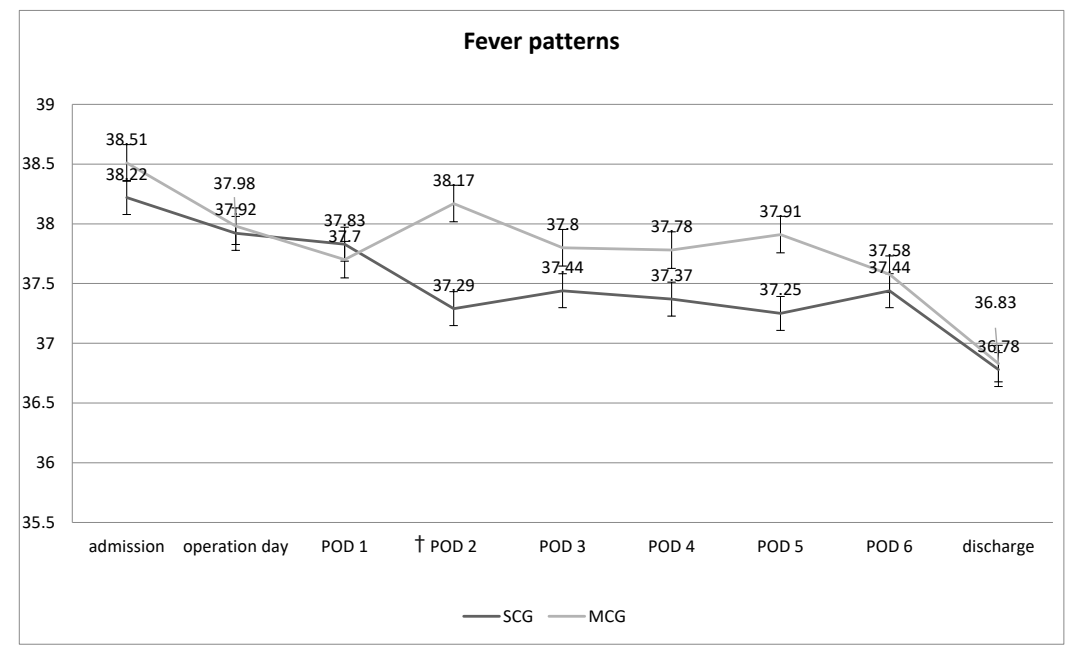

POD - post operative day, $\mathrm{SCG}$ - single complication group, $\mathrm{MCG}$ - multiple complications group

$\dagger$ - statistically significant $(\mathrm{P}=0.035)$ 
Figure 2. Post-operative fever $\geq 38^{0} \mathrm{C}$; SCG and MCG patients

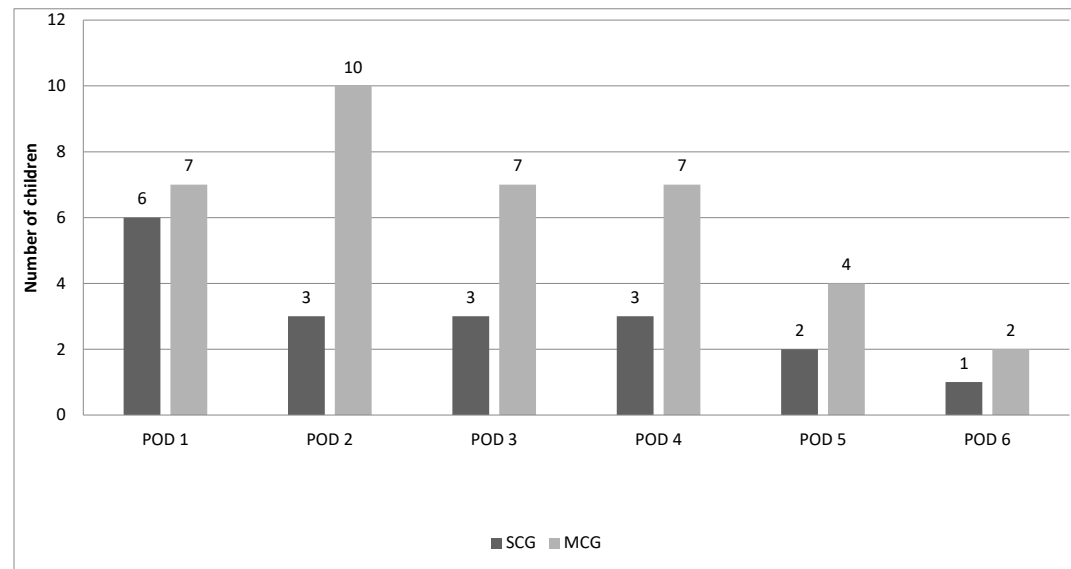

\begin{tabular}{|c|c|c|c|c|c|c|}
\hline POD & 1 & 2 & 3 & 4 & 5 & 6 \\
\hline SCG & $6 / 13$ & $3 / 13$ & $3 / 10$ & $3 / 10$ & $2 / 6$ & $1 / 3$ \\
\hline MCG & $7 / 13$ & $10 / 13$ & $7 / 10$ & $7 / 10$ & $4 / 6$ & $2 / 3$ \\
\hline P-value & 0.728 & 0.013 & 0.141 & 0.141 & 0.398 & 0.601 \\
\hline
\end{tabular}

